\title{
Crack Maintenance Effect Model Testing Study of Mine Construction Metro Lining
}

\author{
Yujie $\mathrm{Li}^{1}$, Huijie $\mathrm{Xu}^{1}$, Guoxia Song ${ }^{1}$, Jianjun $\mathrm{Luo}^{2}$ and Xiaoshi $\mathrm{An}^{1}$ \\ ${ }^{1}$ Beijing Mass Transit Railway Operation Corporation LTD, Beijing 100044, China \\ ${ }^{2}$ School of Civil Engineering, Beijing Jiao tong University, Beijing 100044, China
}

\begin{abstract}
Taking lining structure crack diseases on one line of Beijing subway as the research object, using indoor model test method to studying lining structure damage rule and crack maintenance effect. Through experiment, it was concluded the main conclusions as follows: Through the contrast test could be obtained that, the yield load of crack grouting reinforcement test beams could increased by $6 \% \sim 8 \%$, the ultimate load of test beams could increased by $4 \%$. The main purpose of crack grouting reinforcement technology was to restore structure overall stress form, and the bearing capacity of experimental beams increase is not obvious. The research conclusions have important theoretical guiding significance for the comprehensive treatment work on the tunnel lining structure cracks , which during the next phase.
\end{abstract}

Keywords-lining structure; crack maintenance; model test

\section{INTRODUCTION}

In urban rail transit underground structure, the lining cracks are one of the most common diseases. The causes of lining crack about of the characteristics of concrete itself, low frequency vibration of motor vehicles and the surrounding environment load effect. Because of the different design form, each of the tunnel lining structure damage forms are different [1-3].Related research data shows, Shanghai, Shenzhen, Tianjin, Guangzhou, Nanjing and other urban rail transit city all have structure lining crack, leakage and impellers of various structural diseases [4-9].The root cause of leading to other related disease is the cracks of the lining and development. Some metro line is one of the most important lines in Beijing rail transit. Taking lining structure crack diseases on one line of Beijing subway as the research object, which has important significance to building Beijing "peace metro"[10], and ensuring the safety of capital of the people's travel.

\section{DESIGN OF MODEL EXPERIMENT}

\section{A. Design of Test Beam}

The tunnel structures are composite lining structure, single hole single horseshoe cross section, cross-section profile of tunnel lining structure shows in Figure I. The first tunnel lining is $250 \mathrm{~mm}$ thick steel grille sprayed concrete, and the second tunnel lining is $300 \mathrm{~mm}$ thick plain concrete, some second tunnel lining is steel grille sprayed concrete.

The proportion of test beams using actual tunnel lining size, and take the upper tunnel arch structure as model. The test beam's span is $6100 \mathrm{~mm}$, across is $5000 \mathrm{~mm}$ [11-13].
Test beam used ordinary Portland cement that design strength grade is C20, the coarse aggregate is less than 15 $\mathrm{mm}$ of gravel, the fine aggregate is river sand.The concrete mixture ratio is that cement, water, sand, stone = 1:0.41:1.32:2.45. Steel grating made of the main reinforcement, inclined reinforcement, stirrups and steel plate. The main reinforcement and oblique muscle welding connection, two pieces of steel plates are connected by a bolt. In order to facilitate loading test, it set beam loading platform, test beam supporting structure, and test beam hoisting structure. Test beam design profile shows in Figure II, test beam loading equipment shows in Figure III.

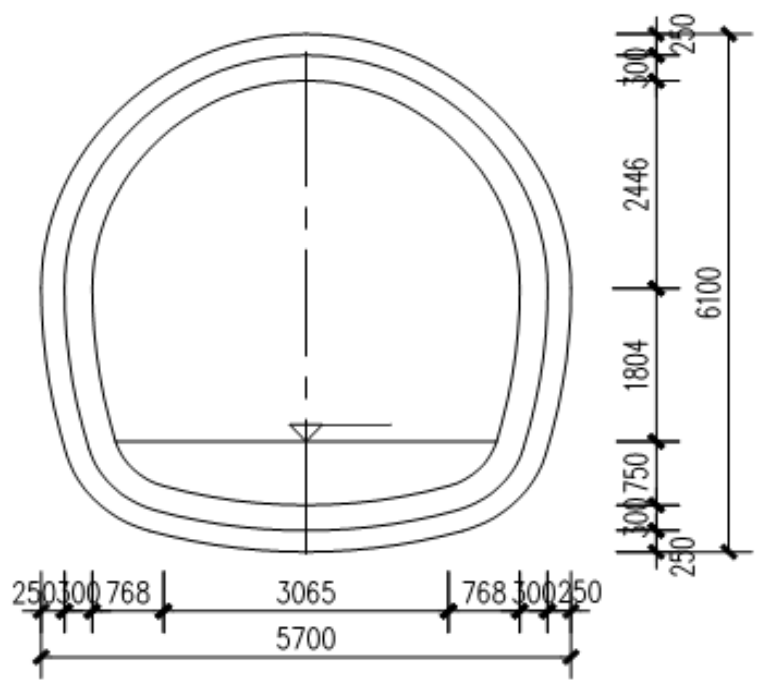

FIGURE I. CROSS-SECTION PROFILE OF TUNNEL LINING STRUCTURE

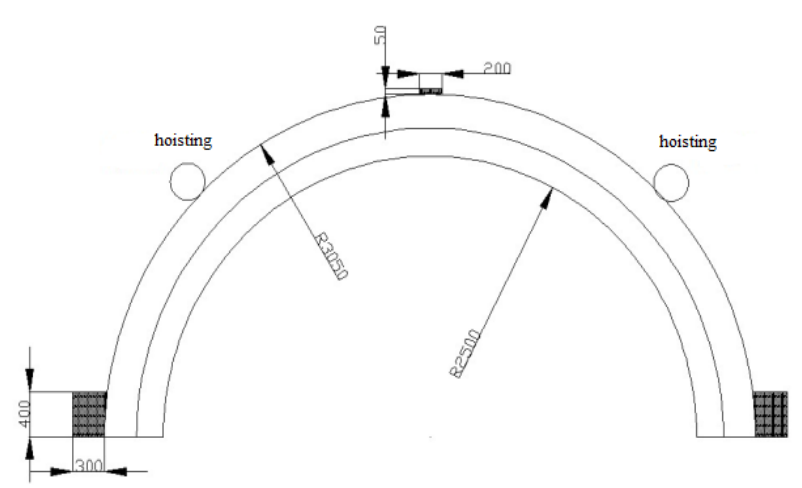

FIGURE II. TEST BEAM DESIGN PROFILE 


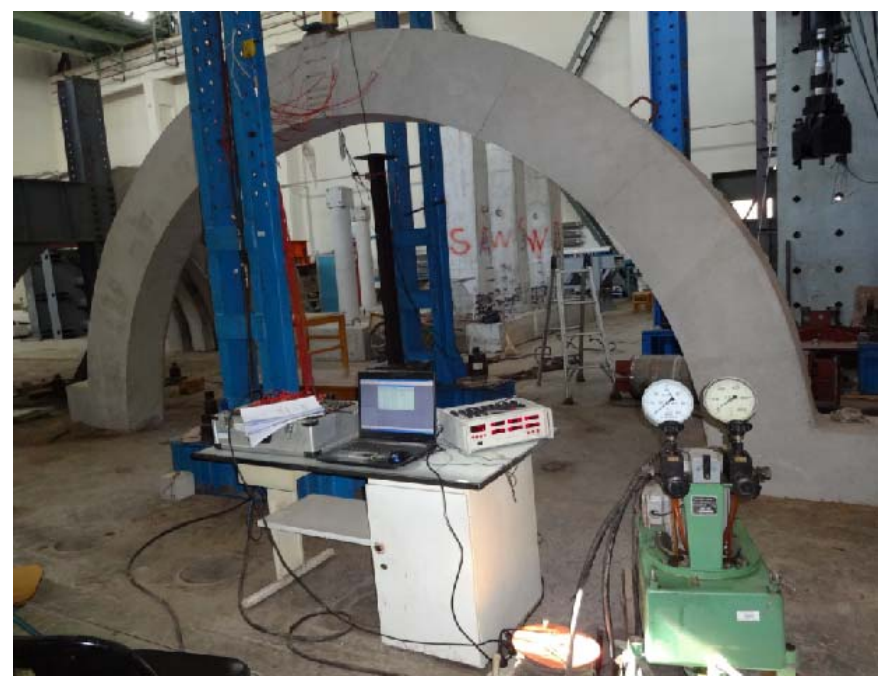

FIGURE III. TEST BEAM LOADING EQUIPMENT

\section{B. Testing Program}

The purpose of the test is mainly as follows: (1)get the damage rule of lining structure by destructive test; (2)through the reinforcement technology of reinforcing effect to obtained the lining structure. It made five experimental beams, respectively for destructive test and the crack repair test under different damage states. Test beam number and damage reinforcement situation shows in table1. The test beam reinforcement construction is completed, a week to maintenance in the laboratory, reinforcing material to carry out the destruction test after the strength to meet the design requirements.

TABLE I. TEST BEAM NUMBER AND DAMAGE REINFORCEMENT SITUATION

\begin{tabular}{|c|c|c|}
\hline number & damage grade & $\begin{array}{c}\text { Structure reinforcing } \\
\text { way }\end{array}$ \\
\hline BM-1 & No damage & NO reinforcement \\
\hline BM-2 & No damage & NO reinforcement \\
\hline BM-3 & No damage & NO reinforcement \\
\hline BM-4 & $\begin{array}{c}\text { After the main crack width up } \\
\text { to } 1.5 \text { mm, unload and } \\
\text { reinforcement }\end{array}$ & $\begin{array}{c}\text { crack grouting } \\
\text { reinforcement }\end{array}$ \\
\hline BM-5 & $\begin{array}{c}\text { After the right crack width up } \\
\text { to } 1.8 \text { mm and the middle } \\
\text { crack width up to } 1.5 \text { mm, } \\
\text { unload and reinforcement }\end{array}$ & $\begin{array}{c}\text { crack grouting } \\
\text { reinforcement }\end{array}$ \\
\hline
\end{tabular}

\section{Damage Level Design}

According to the test purpose, test beam to load before reinforcement, make its injury and craze. Contrast test beam (BM-1, BM-2, BM-3) steel bar strain is used to determine the size of the damage load. The contrast test beam testing take the conclusion that the steel yield strain is $2000 \mu \varepsilon$, test the width of the main crack and the main reinforcement strain has good linear relationship. This test will be the main crack width is $1.5 \mathrm{~mm}$, the corresponding reinforcement strain for $950 \sim 1050 \mu \varepsilon$.

\section{TEST RESULTS AND ANALYSIS}

\section{A. Destruction Process}

Through crack grouting reinforcing experiment beam damage could have the conclusion:

The ultimate destruction form of the test beam mainly about on both sides arch feet and middle arch of the concrete is crush, and test beams rebar yield failure. The crack development law of test beam could be divided into four stages: The first stage for the test load of $110 \mathrm{KN}$, which the reinforcing crack on middle arc has cracking again. The second stage for the test load of $130 \mathrm{KN}$, which the cracks on two side hance have appear. The third stage for the test load of $130 \mathrm{KN} \sim 250 \mathrm{KN}$, which the reinforcing crack develop rapidly. The fourth stage for the test load of $250 \mathrm{KN} \sim 330 \mathrm{KN}$, which the concrete on arc and hance of test beam were crushed, and the transverse cracks were appeared on arc and hance of test beam which cross on longitudinal cracks.

It takes load on test beam to appear crack, then using grouting technology to reinforcement. The crack grouting reinforcement effect shows in Figure IV.After reloaded, most hoping and diagonal bar of test beam are in tension. With the increase of load, the stresses of hoping and diagonal bar near the middle crack are increase. When the test loads go to $110 \mathrm{KN}$, the reinforcing crack on middle arc has cracking again. The grouting reinforcement crack development after reload shows in Figure V.

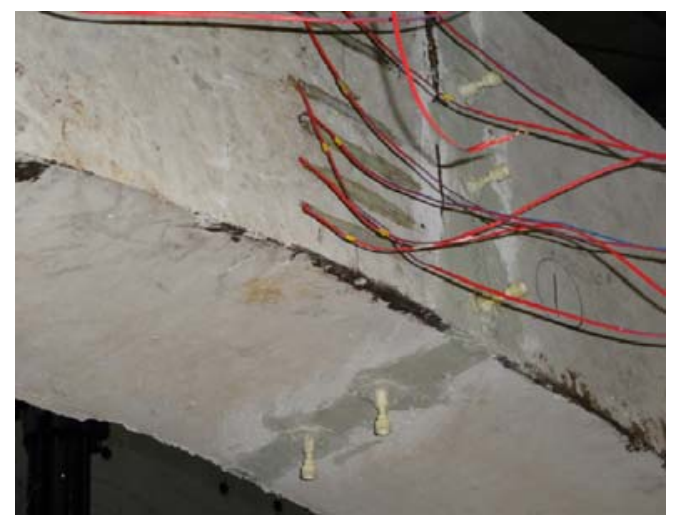

FIGURE IV. CRACK GROUTING REINFORCEMENT EFFECT

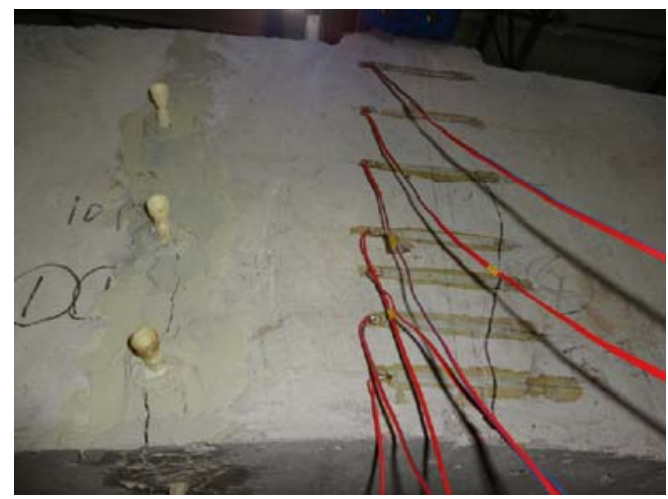

FIGURE V. THE GROUTING REINFORCEMENT CRACK DEVELOPMENT AFTER RELOAD 
In the middle stage (the test load of $110 \mathrm{KN} \sim 190 \mathrm{KN}$ ): When the test loads go to $130 \mathrm{KN}$, the edge position on two side hance of test beam began appear cracks. And these cracks are micro-fracture, which final width is not more than $0.2 \mathrm{~mm}$. The width of reinforcing crack increasing with load increase, the width of the main crack and the stress of main steel bar are linear transformation relation.

In the last stage (the test load of $190 \mathrm{KN} \sim 330 \mathrm{KN}$ ): When the test loads go to $190 \mathrm{KN}$, the main steel bar stage in yield, the width of the main crack and the stress of main steel bar are no-linear transformation relation. The main crack develops rapidly, and it throughout the whole test beam, and there began to appear bifurcation phenomenon on the top and the end of crack. When the last of the test, the concrete of two sides arch springing and arch top are crushed. The stress of steel bars near the main crack is beyond ultimate strength. Some stress of stirrup and oblique muscle obviously decreased. The width of reinforcing middle main crack is $8 \mathrm{~mm}$, the width of crack near two sides arch springing upper concrete are $2 \sim 3 \mathrm{~mm}$, the width of micro-crack less than $0.2 \mathrm{~mm}$. The vault of the maximum deflection is close to 13 mm. Eventually destroy form of reinforcing middle main crack shows in Figure VI.

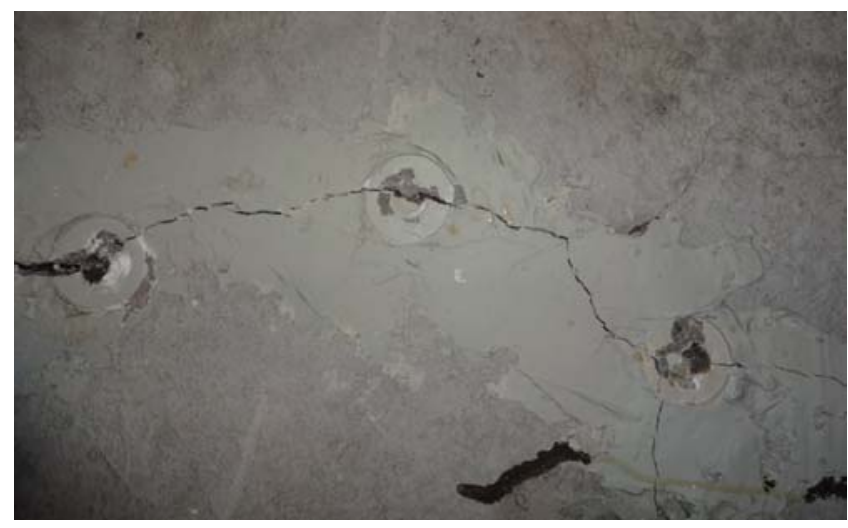

FIGURE VI. EVENTUALLY DESTROY FORM OF REINFORCING MIDDLE MAIN CRACK

Through the crack grouting reinforcing experiments can be obtained, the new crack is still appears in the original reinforcing crack. In the middle test stage, the middle arch appears another crack, but the new crack appears obviously lagging, it shows that the grouting reinforcement could increase the intensity significantly in the early stage. Along the direction of fracture grouting resin uniform distribution, it shows that using the crack grouting construction technology can well ensure the compactness of grouting materials. Grouting material of curing time generally need to reach more than 1 month. Because the test time is tight, curing time is only 1 weeks, the bond strength of grouting material is only $30 \%$ of the ultimate strength. So the damage cracks appear along the existing cracks in the experiments.

\section{B. Force Analysis}

The relation schema of the main reinforcement strain and test load show in Figure VII. It can be obtained that in the whole loading process, relative to the contrast test beam, the main reinforcement strain of test beam experience two mutations, which are reinforcement crack craze and rebar stress beyond the limit. The ultimate load of reinforcing test beam is close to contrast beam. On the basis of the original damage, in the early stages of the load, the strain of the reinforced beam steel is positive, the existing concrete cracking, steel main tensile stress. When the test load at 110 $\mathrm{KN}$ range, steel bar strain once mutations, shows that the beam have craze, as the beam cracking, steel bar strain growing. Reinforcement beam test load in $190 \mathrm{KN}$, steel bar strain is close to 2000, smooth curve in short, the beam has to yield. Test load of $250 \mathrm{KN}$ within the scope of reinforcement is a big mutation, steel bar strain, as the load increases dramatically, strengthening experimental beams reinforced is beyond limit load.

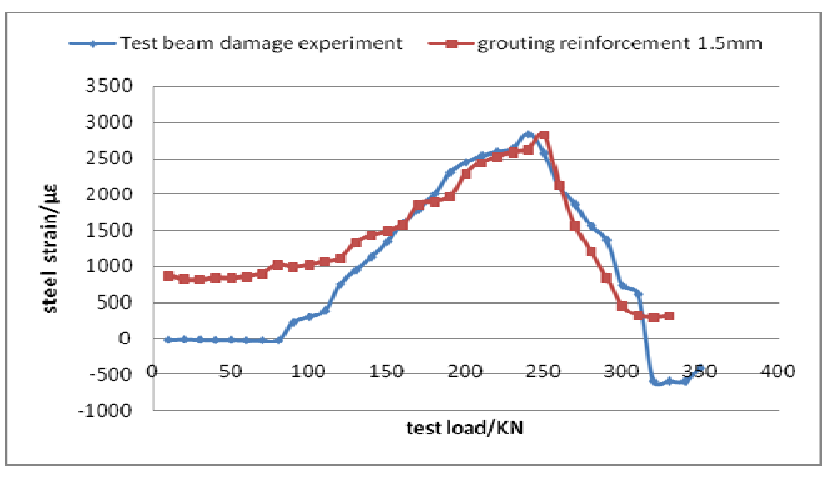

FIGURE VII. RELATION SCHEMA OF THE MAIN REINFORCEMENT STRAIN AND TEST LOAD

\section{CONCLUSION}

Through experiment, it was concluded the main conclusions as follows: Through the contrast test could be obtained that, the yield load of crack grouting reinforcement test beams could increased by $6 \% \sim 8 \%$, the ultimate load of test beams could increased by $4 \%$. The main purpose of crack grouting reinforcement technology was to restore structure overall stress form, and the bearing capacity of experimental beams increase is not obvious. The research conclusions have important theoretical guiding significance for the comprehensive treatment work on the tunnel lining structure cracks, which during the next phase.

\section{ACKNOWLEDGMENT}

This article subsidize by Beijing subway operation co., LTD. scientific research project (2013000510000017) (2015000510000008).

\section{REFERENCES}

[1] Wang Mengshu. Chinese tunnel and underground engineering construction technology [M]. Beijing: China Communications Press, 2010.

[2] Guan Baoshu. Tunnel maintenance manual [R]. Chengdu: southwest jiaotong university, 1994:69-75.

[3] Guan Baoshu. Variation measures tunnel design manual [Z]. Railway comprehensive technology research institute in Japan, 1998-39-53. 
[4] Hu Yidong. EAA epoxy materials in guangzhou metro line 1 the application of the solid bed disease management [J]. Journal of research in urban rail transit, 2005, 8 (6) : 75-77.

[5] Yu Jian, He Chuan. Tunnel secondary lining disease general treatment method research [J]. China railway science, 2005, 26 (1) : 25 to 30.

[6] Li-min peng, QinChangBing, cheng-hua shi etc. Field test research on railway tunnel base defect [J]. China railway science, 2005, 26 (2) : 39-43.

[7] Zhu Zuxi. Comprehensive development of underground engineering seepage of deformation joint [J]. Chinese building waterproof, 2013, (1) : 225.

[8] Sheng Tangxing. Shenzhen metro station structure crack leakage control [J]. Journal of tunnel construction, 2005, 25 (z1) : 52-55.

[9] Li ping. Tianjin metro line 1 of existing track structure renovation scheme for preventing disease research [J]. Journal of railway engineering, 2004, (7) : 72-74.

[10] Xie zhengguang. Construction of "six metro" further enhance the level of Beijing subway operation service [J]. Journal of urban rapid rail transit, 2012, 25 (5).

[11] Yu-jie li, wang, xu jie, zhang yuan. Fiber cloth reinforcing numerical analysis of metro tunnel structure [J]. Journal of civil engineering, 2014,47 (8) : 138-144.

[12] Yu-jie li, wang, xu jie, zhang yuan. Fiber cloth reinforcing the subway tunnel structure yu-jie li, wang, xu jie, Jiang Liang. Carbon fiber reinforced mining method of metro tunnel lining structure simulation [M]. / / 2013 China's urban rail transit key technology BBS. 2013:328-333;

[13] Yu jie Li, Hui jie Xu, Yuan Zhang, Juan JuanYao. Application of carbon fiber cloth in reinforcement of metro tunnel disease,[C].//CEABM 2013:.1525-1528. 